\title{
Equilibrium Indeterminacy, Endogenous Entry and Exit, and Increasing Returns to Specialization*
}

\author{
Shu-Hua Chen ${ }^{\dagger}$ \\ National Taipei University
}

\author{
Jang-Ting Guo ${ }^{\ddagger}$ \\ University of California, Riverside
}

April 21, 2020

\begin{abstract}
This paper systematically examines the interrelations between equilibrium indeterminacy, endogenous entry and exit of intermediate-input firms, and increasing returns to specialization within two versions of a parsimonious one-sector monopolistically competitive real business cycle model. The technology for producing an intermediate good is postulated to display internal increasing returns-to-scale in our benchmark framework, whereas positive productive externalities are considered in the alternative setting. We analytically show that either formulation will exhibit belief-driven cyclical fluctuations if and only if the equilibrium wage-hours locus is positively sloped and steeper than the household's labor supply curve. We also find that ceteris paribus our alternative macroeconomy is more susceptible to indeterminacy and sunspots than the baseline counterpart.
\end{abstract}

Keywords: Equilibrium Indeterminacy; Endogenous Entry and Exit; Increasing Returns to Specialization.

JEL Classification: E13, E32, O41.

\footnotetext{
${ }^{*}$ We thank Juin-Jen Chang, Been-Lon Chen, Miroslav Gabrovski, Sharon Harrison, Victor Ortego-Marti, Wei-Neng Wang and Mark Weder for helpful comments and discussions. Part of this research was conducted while Guo was a visiting research fellow of economics at Academia Sinica, Taipei, Taiwan, whose hospitality is greatly appreciated. Of course, all remaining errors are our own.

${ }^{\dagger}$ Department of Economics, National Taipei University, 151 University Rd., San Shia, Taipei, 237 Taiwan, Phone: 886-2-8674-7168, Fax: 886-2-2673-9727, E-mail: shchen@mail.ntpu.edu.tw.

${ }^{\ddagger}$ Corresponding Author. Department of Economics, 3133 Sproul Hall, University of California, Riverside, CA 92521, USA, Phone: 1-951-827-1588, Fax: 1-951-827-5685, E-mail: guojt@ucr.edu.
} 


\section{Introduction}

In an influential piece of work, Benhabib and Farmer (1994) have shown that slight departures from an otherwise standard one-sector real business cycle (RBC) model, in the form of either productive externalities or monopolistic competition, may lead to equilibrium indeterminacy and belief-driven aggregate fluctuations. ${ }^{1}$ For the sake of analytical simplicity within their monopolistically competitive setting, these authors postulate a time-invariant measure of intermediate goods-producing firms, which in turn implies that positive profits will exist in equilibrium because entry and exit of intermediate-input producers are not allowed; and that returns to product variety are completely absent. In this paper, we incorporate the following empirically realistic features into the Benhabib-Farmer economy: variations in the measure of intermediate-good producers over time, together with the associated increasing returns to specialization. $^{2}$ In addition, the parameters that govern the degree of the monopolistic market power versus the strength of variety effects are disentangled. Accordingly, the primary objectives of our study are to examine the robustness of Benhabib and Farmer's (1994) theoretical findings under the aforementioned extensions, as well as to further understand the precise economic mechanisms through which multiple equilibria may occur in a one-sector representative-agent macroeconomy with imperfectly competitive markets.

In the context of two versions of a parsimonious one-sector monopolistically competitive $\mathrm{RBC}$ model, we examine the analytical and quantitative interrelations between macroeconomic instability, free entry/exit of intermediate-input firms and increasing returns to product variety. Specifically, other than the common fixed set-up costs, additional increasing returns-to-scale for producing intermediate goods in the baseline economy are originated from operational firms' own factor inputs à la Benhabib and Farmer (1994, section 2.2); whereas positive productive externalities from the economy-wide levels of capital and labor services are the sources in the alternative framework à la Chang, Hung and Huang (2011). Each formulation has an intermediate-good segment in which monopolistically competitive firms operate with a CobbDouglas production function and pre-set constant overhead costs. The equilibrium measure of these intermediate-input producers is determined endogenously through the condition of zero profits. This in turn yields increasing returns to specialization, as in Bénassy (1996), that

\footnotetext{
${ }^{1}$ See Benhabib and Farmer (1999) for an early survey of this RBC-based indeterminacy literature.

${ }^{2}$ Previous research that has provided empirical support for the importance of entry and exit (or births and deaths) of firms/products over the business cycle includes Davis and Haltiwangar (1990), Jaimovich and Floetotto (2008), Bernard, Redding and Schott (2010), and Broda and Weinstein (2010), among others. In terms of existent studies that have reported estimation results to affirm the incidence of positive variety effects, see, for example, Funke and Ruhwedel (2001), Feenstra and Lee (2008), and Ardelean (2011).
} 
will appear in the economy's social technology. A single final output (GDP) is produced from combining available differentiated intermediate goods in a perfectly competitive environment.

For the baseline economy, we derive the analytical expression of its Jacobian matrix evaluated at the unique interior stationary state, and then show that the necessary and sufficient condition for local indeterminacy is an upward-sloping equilibrium wage-hours locus which is steeper than the household's labor supply curve. It follows that endogenous aggregate booms and downturns may occur as self-fulfilling sunspot equilibria. This requisite condition turns out to be qualitatively the same as that for an indeterminate steady state to arise in Benhabib and Farmer's (1994) one-sector RBC macroeconomy without creation/destruction of intermediate inputs-producing firms and returns to specialization. In accordance with Kim (2004, section 3.2), we also find that the level of intermediate-good producers' market power has no bearing on the benchmark model's macroeconomic (in)stability properties because their monopolistic markup does not affect the symmetric-equilibrium prices of intermediate goods and factor inputs. As pointed out by Bénassy (1996), the feature of intermediate-input firms' monopoly power is only necessary for the existence of a monopolistically competitive equilibrium in light of the incidence of fixed set-up costs. It is worth noting that this is a result that cannot be arrived at when a single parameter is adopted to characterize not only the variety range, but also the size of market power, for producing intermediate goods, as in Devereux, Head and Lapham (1993, 1996, 2000) and Chang, Hung and Huang (2011).

To gain further insights of the aforementioned indeterminacy condition, we undertake a two-part comparative analysis and obtain the following results. First, our baseline model's reduced-form production function is found to display constant returns-to-scale in aggregate levels of capital and labor services under no returns to product variety. In this case, the economy always exhibits saddle path-stability stability and equilibrium uniqueness. This finding implies that incorporating endogenous entry and exit of intermediate-input producers alone (without the accompanying returns to specialization) into Benhabib and Farmer's (1994, section 2.2) one-sector monopolistically competitive RBC model will eliminate the possibility of indeterminacy and sunspots altogether. Second, we analytically show that in comparison with the original Benhabib-Farmer macroeconomy, our benchmark framework is ceteris paribus more (less) likely to possess indeterminate equilibria when the gross rate of return from variety effects is higher (lower) than the total internal returns-to-scale in production originated from intermediate goods-producing firms' own factor inputs.

For the alternative economy, it is straightforward to show that as in our benchmark formulation, the magnitude of market power for intermediate-good producers exerts no influence 
on the model's equilibrium dynamics since the corresponding monopolistic-markup parameter does not enter the associated Jacobian matrix. It can also be shown that the intuitive interpretation of its necessary and sufficient condition for local indeterminacy is qualitatively identical to that within our baseline or Benhabib and Farmer's (1994, section 2.2) setting, i.e. the positively-sloped equilibrium wage-hours locus needs to intersect the household's labor supply curve from below. Per a similar two-part comparative examination as described above, we find that in sharp contrast to our benchmark specification, macroeconomic instability may still arise in the modified model under no returns to specialization because the resulting social technology exhibits increasing returns-to-scale in the economy-wide capital and labor inputs due to the presence of positive external effects. It follows that a sufficiently high level of productive externalities from aggregate labor hours alone (without any variety effects) is able to generate belief-driven cyclical fluctuations within the alternative macroeconomy. Moreover, we analytically derive the inequality under which the parametric scope for endogenous business cycles will be ceteris paribus larger/smaller in our modified model than that in the Benhabib-Farmer framework. As it turns out, the sign for this condition is determined by the combined effects of labor externalities and returns to specialization versus the markup ratio of price over marginal costs.

Although the requisite conditions for indeterminacy and sunspots are intuitively the same in our baseline as well as alternative formulations, their quantitative implications are different. Specifically, there are two complementary factors in producing multiple equilibria within the modified model: either a stronger external effect of aggregate labor inputs or an increase in the equilibrium measure of intermediate goods will raise the output elasticity with respect to hours worked in the economy's social technology, which in turn helps fulfill agents' optimistic expectations about future economic activities. As a consequence, the minimum degree of returns to specialization needed for macroeconomic instability is found to be monotonically decreasing in the level of labor externalities. On the contrary, only the product-variety parameter is available to affect the local (in)stability properties of the benchmark model. It follows that while keeping the calibrated values of other parameters unchanged, it will be quantitatively more likely for our alternative macroeconomy to display belief-driven cyclical fluctuations than the baseline counterpart. This result thus illustrates the critical importance of intermediate inputs-producing firms' production specifications on the feasible parametric region that exhibits an indeterminate steady state within a one-sector RBC model under monopolistic competition, endogenous entry and exit of firms, and increasing returns to specialization.

Finally, per the criticism that Benhabib and Farmer (1994) have been is subjected to, we 
acknowledge that the threshold level of aggregate returns-to-scale in production needed for local indeterminacy within either our baseline or alternative economy is unrealistically high vis-à-vis estimation results of previous empirical studies. However, this is not a serious issue of concern in light of subsequent theoretical developments in the RBC-based indeterminacy literature. For example, it has been shown that in a one-sector RBC model with variable capital utilization (Wen, 1998) or countercyclical income taxation (Schmitt-Grohé and Uribe, 1997); or in a two-sector RBC model with sector-specific productive externalities (Benhabib and Farmer, 1996; Perli, 1998; and Harrison, 2001), the minimum degree of technological increasing returns required for the occurrence of endogenous business cycles is much less stringent. Since asserting the empirical plausibility of equilibrium multiplicity is not an objective of this paper, we plan to incorporate one of the above-mentioned features into our benchmark and alternative formulations in future research. On the other hand, maintaining the parsimonious structure close to the original Benhabib-Farmer monopolistically competitive setting will allow the comparison of our versus their theoretical and quantitative results to be conducted in a focused and transparent manner.

The remainder of this paper is organized as follows. Section 2 describes our benchmark model, discusses its equilibrium conditions, and then analytically as well as quantitatively examines the resulting local (in)stability properties. Section 3 studies the macroeconomic dynamics of our alternative economy. Section 4 concludes.

\section{The Economy}

Our analysis begins with incorporating (i) free entry and exit of intermediate goods-producing firms, and (ii) distinct parameters that govern the degree of intermediate-input producers' monopoly power versus the level of increasing returns to specialization into Benhabib and Farmer's (1994, section 2.2) parsimonious one-sector real business cycle model with monopolistic competition in continuous time. Households live forever, and derive utilities from consumption and leisure. The production side of the economy consists of an intermediate-good segment in which monopolistically competitive firms operate under fixed set-up costs and internal constant/increasing returns-to-scale in production from their own capital and labor inputs. The equilibrium measure of these intermediate-input producers is endogenously determined through the zero-profit condition. This in turn generates increasing returns to specialization or product variety, à la Bénassy (1996), that will appear in the economy's social technology. A final output (GDP) is produced from the set of available differentiated intermediate goods in a perfectly competitive environment. We also postulate that there are no fundamental 
uncertainties present in the macroeconomy.

\subsection{Firms}

The production side of our model economy is comprised of two segments. A single final good $Y_{t}$ is produced from a continuum of intermediate inputs $x_{j t}$ through the following production technology:

$$
Y_{t}=N_{t}^{1+\theta-\frac{1}{\lambda}}\left(\int_{0}^{N_{t}} x_{j t}^{\lambda} d j\right)^{\frac{1}{\lambda}}, \theta>0 \text { and } 0<\lambda<1,
$$

where $N_{t}$ denotes the measure of (or the degree of variety for) intermediate goods utilized in period $t, \theta$ represents the degree of returns to specialization as in Bénassy (1996), and $\lambda$ determines the elasticity of substitution between intermediate inputs. The final-good segment is postulated to be perfectly competitive, and we denote $p_{j t}$ as the price of the $j$ 'th intermediate good relative to the final output. The final goods-producing firms' profit maximization condition yields that the demand function for $x_{j t}$ is

$$
x_{j t}=\left[\frac{N_{t}^{\lambda\left(1+\theta-\frac{1}{\lambda}\right)}}{p_{j t}}\right]^{\frac{1}{1-\lambda}} Y_{t},
$$

where the elasticity of demand is $\frac{1}{1-\lambda}$, and the resulting markup ratio of price over marginal cost is equal to $\frac{1}{\lambda}$. In the limiting case of $\lambda=1$, all intermediate inputs are perfect substitutes for the production of $Y_{t}$, hence the demand curve (2) will become perfectly elastic or horizontal. In addition, the parameters that characterize the degree of market power for intermediate-good firms $\lambda$ and the level of product variety $\theta$ are now disentangled.

In our benchmark model, each intermediate good is produced by a monopolist with the production function that allows for constant à la Bénassy (1996) or increasing à la Benhabib and Farmer (1994) returns-to-scale in its own factor inputs:

$$
x_{j t}=k_{j t}^{\alpha} h_{j t}^{\beta}-F, \quad \alpha, \beta, F>0 \text { and } \alpha+\beta \geq 1 \text {, }
$$

where $k_{j t}$ and $h_{j t}$ are capital and labor services employed by the $j$ 'th intermediate-input producer; and $F$ represents a constant amount of intermediate goods that must be expended as fixed set-up costs before any production is undertaken. When $\alpha+\beta=1$, the presence of such overhead costs implies that the intermediate-good technology exhibits increasing returns- 
to-scale. ${ }^{3}$ Moreover, additional increasing returns will exist in (3) under $\alpha+\beta>1$ because of diminishing marginal costs.

Using equations (2) and (3), the profit function for the intermediate-input producer $j$ is given by

$$
\pi_{j t}=\left[N_{t}^{1+\theta-\frac{1}{\lambda}} x_{j t}\right]^{\lambda} Y_{t}^{1-\lambda}-r_{t} k_{j t}-w_{t} h_{j t},
$$

where $r_{t}$ is the capital rental rate and $w_{t}$ is the real wage rate. Given the assumption that factor markets are perfectly competitive, it is straightforward to show that the first-order conditions for the $j$ 'th intermediate-good firm's profit maximization problem are

$$
r_{t}=\frac{\lambda \alpha\left(x_{j t}+F\right) p_{j t}}{k_{j t}} \text { and } w_{t}=\frac{\lambda \beta\left(x_{j t}+F\right) p_{j t}}{h_{j t}} .
$$

Under the maintained assumption of free entry and exit for intermediate goods-producing firms, their profit will be equal to zero at each instant of time. This zero-profit condition in conjunction with (5) lead to the constant equilibrium quantity of intermediate input $j$ :

$$
x_{j t}=\frac{\lambda(\alpha+\beta) F}{1-\lambda(\alpha+\beta)},
$$

where $\lambda(\alpha+\beta)<1$ to ensure that $x_{j t}$ is strictly positive. ${ }^{4}$ This expression also represents the size of the $j$ 'th intermediate-good producer that turns out to be independent of any endogenous variable. In what follows, our analysis is restricted to the model's symmetric equilibria in which

$$
p_{j t}=p_{t}, \quad x_{j t}=x_{t}, \quad k_{j t}=\frac{K_{t}}{N_{t}}, \quad h_{j t}=\frac{H_{t}}{N_{t}}, \text { for all } j \in\left[0, N_{t}\right]
$$

where $K_{t}\left(=\int_{0}^{N_{t}} k_{j t} d j\right)$ and $H_{t}\left(=\int_{0}^{N_{t}} h_{j t} d j\right)$ represent the total capital stock and labor hours demanded or employed by intermediate-input firms. Using equations (3), (6) and (7) yields that the equilibrium measure of intermediate-good producers is

$$
N_{t}=\left\{\frac{[1-\lambda(\alpha+\beta)] K_{t}^{\alpha} H_{t}^{\beta}}{F}\right\}^{\frac{1}{\alpha+\beta}}>0 .
$$

Next, after substituting (7)-(8) into (1) and (2), we find that the economy's reduced-form aggregate production functions is given by

\footnotetext{
${ }^{3}$ As in our baseline economy, the one-sector RBC model of Devereux, Head and Lapham (DHL; 1993, 1996, 2000) also considers monopolistic competition under $\alpha+\beta=1$, together with endogenous entry and exit of intermediate-input producers. However, DHL postulate that the degree of returns to specialization takes on the specific value $\theta=\frac{1}{\lambda}-1>0$. It follows that there exists a one-to-one link between $\lambda$ and $\theta$, whereas these two parameters are differentiated in our analysis.

${ }^{4}$ It can be shown that under a less stringent parametric restriction $\lambda(\alpha+\beta) \leq 1$, the second-order or concavity condition on (4) will be satisfied.
} 


$$
Y_{t}=N_{t}^{1+\theta} x_{t}=\left\{\lambda(\alpha+\beta)\left[\frac{1-\lambda(\alpha+\beta)}{F}\right]^{\frac{1+\theta}{\alpha+\beta}-1}\right\}_{\equiv \Omega>0} K_{t}^{\frac{\alpha(1+\theta)}{\alpha+\beta}} H_{t}^{\frac{\beta(1+\theta)}{\alpha+\beta}},
$$

where $\frac{\alpha(1+\theta)}{\alpha+\beta}<1$ to rule out the possibility of sustained endogenous growth and $N_{t}^{1+\theta}$ represents a productivity measure. Since the specialization parameter $\theta>0$, the social technology (9) will exhibit increasing returns to an expansion in product variety $N_{t}$, which can be interpreted as endogenously enhancing the total factor productivity. In addition, as pointed out by Kim (2004, section 2.4), the degree of intermediate goods-producing firms' constant market power $\lambda$ does not affect the level of aggregate returns-to-scale in production $(=1+\theta)$ within our monopolistically competitive RBC model under time-invariant set-up costs $F$ and zero profits at each instant of time. Finally, plugging (7) and (9) into (2) shows that the symmetric-equilibrium price of each intermediate good is

$$
p_{t}=N_{t}^{\theta}
$$

We can then combine equations (5)-(10) to obtain that the symmetric-equilibrium factor prices are given by

$$
r_{t}=\frac{\alpha Y_{t}}{(\alpha+\beta) K_{t}} \quad \text { and } \quad w_{t}=\frac{\beta Y_{t}}{(\alpha+\beta) H_{t}}
$$

hence the capital and labor shares of national income are $\frac{\alpha}{\alpha+\beta}$ and $\frac{\beta}{\alpha+\beta}$, respectively. Notice that the equilibrium prices of intermediate goods and factor inputs are all independent of the monopolistic-markup parameter $\lambda$.

\subsection{Households}

The economy is populated by a unit measure of identical infinitely-lived households, each of which maximizes a discounted stream of utilities over its lifetime:

$$
\int_{0}^{\infty}\left(\log C_{t}-A \frac{H_{t}^{1+\gamma}}{1+\gamma}\right) e^{-\rho t} d t, A \text { and } \rho>0,
$$

where $C_{t}$ is consumption, $\gamma \geq 0$ denotes the inverse of the intertemporal elasticity of substitution in labor supply, and $\rho$ is the subjective rate of time preference. The budget constraint faced by the representative agent is given by

$$
\dot{K}_{t}=\underbrace{w_{t} H_{t}+r_{t} K_{t}}_{=Y_{t}}-C_{t}-\delta K_{t}, K_{0}>0 \text { given, }
$$


where $\delta \in(0,1)$ is the capital depreciation rate. The first-order conditions for the household's dynamic optimization problem are

$$
\begin{gathered}
A C_{t} H_{t}^{\gamma}=w_{t}, \\
\frac{\dot{C}_{t}}{C_{t}}=r_{t}-\delta-\rho, \\
\lim _{t \rightarrow \infty} e^{-\rho t} \frac{K_{t}}{C_{t}}=0,
\end{gathered}
$$

where (14) equates the slope of the representative agent's indifference curve to the real wage, (15) is the consumption Euler equation and (16) is the transversality condition.

\subsection{Macroeconomic (In)stability}

To facilitate the analysis of local (in)stability properties within the baseline economy, we make the following logarithmic transformation of variables: $k_{t} \equiv \log \left(K_{t}\right)$ and $c_{t} \equiv \log \left(C_{t}\right)$. With these transformations, our model's equilibrium conditions can be expressed as an autonomous pair of differential equations:

$$
\begin{aligned}
& \dot{k}_{t}=e^{\lambda_{0}+\lambda_{1} k_{t}+\lambda_{2} c_{t}}-\delta-e^{c_{t}-k_{t}}, \\
& \dot{c}_{t}=\left(\frac{\alpha}{\alpha+\beta}\right) e^{\lambda_{0}+\lambda_{1} k_{t}+\lambda_{2} c_{t}}-\rho-\delta,
\end{aligned}
$$

where

$$
\begin{gathered}
\lambda_{0}=\left[\frac{(\alpha+\beta)(1+\gamma)}{(\alpha+\beta)(1+\gamma)-\beta(1+\theta)}\right] \log \Omega-\left[\frac{\beta(1+\theta)}{(\alpha+\beta)(1+\gamma)-\beta(1+\theta)}\right] \log \left[\frac{A(\alpha+\beta)}{\beta}\right], \\
\lambda_{1}=\frac{\theta(\alpha+\beta)+\gamma(\alpha \theta-\beta)}{(\alpha+\beta)(1+\gamma)-\beta(1+\theta)} \quad \text { and } \quad \lambda_{2}=\frac{-\beta(1+\theta)}{(\alpha+\beta)(1+\gamma)-\beta(1+\theta)} .
\end{gathered}
$$

It is straightforward to show that the above dynamical system possesses a unique interior stationary state. We can then derive the Jacobian matrix of partial derivatives for the transformed dynamical system (17)-(18) evaluated at this steady state. The determinant and trace of the model's Jacobian $\mathbf{J}$ are given by

$$
\operatorname{Det}=\underbrace{\left\{\frac{(\rho+\delta)[\beta \delta+\rho(\alpha+\beta)]}{\alpha}\right\}}_{\text {positive }}\left\{\frac{(1+\gamma)[\alpha(1+\theta)-(\alpha+\beta)]}{(\alpha+\beta)(1+\gamma)-\beta(1+\theta)}\right\},
$$


and

$$
\operatorname{Tr}=\frac{\delta \theta(\alpha+\beta)(1+\gamma)+\rho(1+\theta)[\alpha(1+\gamma)+\beta \gamma]}{(\alpha+\beta)(1+\gamma)-\beta(1+\theta)} .
$$

Since the first-order dynamical system (17)-(18) possesses one predetermined variable $k_{t}$, the economy displays saddle-path stability and equilibrium uniqueness if and only if the two eigenvalues of $\mathbf{J}$ are of opposite sign $($ Det $<0)$. When both eigenvalues have negative real parts $($ Det $>0$ and $\operatorname{Tr}<0)$, the steady state is a locally indeterminate sink that can be exploited to generate endogenous business cycles driven by agents' self-fulfilling expectations or sunspots. The steady state becomes a source when both eigenvalues have positive real parts (Det $>0$ and $T r>0$ ). In this case, any trajectory that diverges away from the completely unstable steady state may settle down to a limit cycle or to some more complicated attracting sets.

We first note that in accordance with Kim (2004, section 3.2), the level of intermediateinput producers' monopolistic markup has no bearing on our model's macroeconomic (in)stability properties because $\lambda \in(0,1)$ does not affect the symmetric-equilibrium prices of intermediate goods and factor inputs (see equations 10 and 11), nor the Jacobian matrix's determinant and trace given by (19)-(20). As pointed out by Bénassy (1996), the feature of market power is only necessary for the existence of a monopolistically competitive equilibrium, characterized by (6) and (8), in light of the incidence of fixed set-up costs $F .^{5}$ Notice that this is a result that cannot be obtained when a single parameter is adopted to govern not only the variety range, but also the size of monopoly power, for producing intermediate goods, as in Devereux, Head and Lapham (1993, 1996, 2000) and Chang, Hung and Huang (2011). Next, given $\alpha, \beta, \theta, \rho>0$, $\gamma \geq 0,0<\delta<1$, together with $\alpha(1+\theta)<\alpha+\beta$ to rule out the possibility of sustained endogenous growth (see equation 9), the numerator of the second curly brace in (19) is negative. It follows that the Jacobian's determinant (19) is positive when $(\alpha+\beta)(1+\gamma)<\beta(1+\theta)$, which can be re-written as

$$
\frac{\beta(1+\theta)}{\alpha+\beta}-1>\gamma
$$

Moreover, since the numerator of the Jacobian's trace (20) is positive under all feasible parametric configurations, the inequality reported in (21) not only leads to a positive determinant, but also guarantees a negative trace, indicating the presence of two eigenvalues with negative

\footnotetext{
${ }^{5}$ As a result, Bénassy (1996) shows that the occurrence of additional output persistence found in Devereux, Head and Lapham's (1993) monopolistically competitive model is entirely attributed to the presence of positive product-variety effects.
} 
real parts. This implies that (21) is the necessary and sufficient condition for our baseline macroeconomy to exhibit equilibrium indeterminacy and belief-driven cyclical fluctuations. By contrast, when the condition of (21) is not satisfied, the Jacobian matrix $\mathbf{J}$ will possess a negative determinant, hence the model's steady state becomes a saddle point that is locally determinate or unique.

To understand the above indeterminacy condition, substituting the social technology (9) into the logarithmic version of intermediate-good firms' labor demand function, given by the second part of (11), shows that the slope of the equilibrium wage-hours locus is $\frac{\beta(1+\theta)}{\alpha+\beta}-1$; whereas using the logarithmic version of (14) yields that the slope of the household's labor supply curve is $\gamma \geq 0$. As a result, the necessary and sufficient condition needed for our baseline economy to exhibit a continuum of stationary sunspot equilibria stipulates that the equilibrium wage-hours schedule is upward sloping and steeper than the labor supply curve. Intuitively, start from the model's steady state, and suppose that agents anticipate an increase in future economic activities. It follows that the representative household will consume less and invest more today, which in turn increase next period's capital stock, hours worked, output, and consumption. Our preceding analysis finds that adding increasing returns to specialization with $\theta>0$ raises the elasticity of the reduced-form aggregate production function with respect to hours worked, as shown in equation (9). In addition, agents' initial optimistic expectations will be fulfilled if and only if the product-variety effects are sufficiently strong to make the equilibrium wage-hours locus intersect the household's labor supply curve from below such that inequality (21) is satisfied.

To gain additional insights of condition (21), we undertake a two-part comparative analysis as follows. First, consider our benchmark model without any returns to specialization, i.e. $\theta=0$ in the final-output production function (1) and all the subsequent derivations. In this case, the social technology (9) will exhibit constant returns-to-scale in $K_{t}$ and $H_{t}$, which in turn implies that the Jacobian's determinant (19) must be negative because its denominator $(\alpha+\beta)(1+\gamma)-\beta>0$ for all feasible combinations of $\alpha, \beta$ and $\gamma$. Therefore, the economy always displays saddle path-stability stability and equilibrium uniqueness. This result also implies that incorporating endogenous entry and exit of intermediate-good producers alone (without the accompanying product-variety effects) into Benhabib and Farmer's (1994, section 2.2 ) one-sector monopolistically competitive RBC macroeconomy will completely remove the possibility of an indeterminate steady state. Second, consider the original Benhabib-Farmer model under a constant measure of intermediate inputs over time $\left(N_{t}=1\right.$ in equation 1$)$, in conjunction with no fixed set-up costs $(F=0$ in equation 3$)$. In this setting, intermediate 
goods-producing firms will make positive profits in equilibrium since their entry and exit are not allowed; and returns to product variety are entirely absent. Using the notations adopted in this section, it is straightforward to derive that the Benhabib-Farmer macroeconomy exhibits belief-driven cyclical fluctuations if and only if

$$
\beta-1>\gamma
$$

A side-by-side comparison of (21) versus (22) will then show that under the same labor supply elasticity governed by $\gamma$, the parametric scope of indeterminacy and sunspots is larger (smaller) in our baseline formulation than that in Benhabib and Farmer's (1994) framework provided $1+\theta>(<) \alpha+\beta$. That is, the benchmark model is ceteris paribus more (less) likely to possess multiple equilibria when the gross rate of return from variety effects is higher (lower) than the total internal returns-to-scale in production originated from intermediate-good firms' own factor inputs. In sum, we have analytically shown that the required parameterizations for macroeconomic instability are quantitatively different across these two model economies.

On the other hand, we note that the underlying economic intuition for conditions (21) and (22) turns out to be qualitatively identical. This finding in turn implies that as in the Benhabib-Farmer model, the requisite level of aggregate increasing returns-to-scale in production for a continuum of stationary sunspot equilibria to arise within our baseline macroeconomy is implausibly high. As an illustrative example, under the commonly-adopted parameterization that calibrates the labor share of national income $\frac{\beta}{\alpha+\beta}=0.7$ and the indivisible-labor supply elasticity $\gamma=0$, the minimum degree of returns to specialization required to satisfy the inequality of $(21)$ is $\theta_{\min }=0.4286$. While there is no general consensus on the point estimates of this variety-specific parameter in the existing empirical literature, the resulting social returns-to-scale $\left(=1+\theta_{\min }\right)$ is not empirically plausible visof Burnside (1996), Basu and Fernald (1997), and Laitner and Stolyarov (2004), among others. In the RBC-based indeterminacy literature, theoretical developments have shown that in a one-sector RBC model with variable capital utilization (Wen, 1998) or countercyclical distortionary taxation (Schmitt-Grohé and Uribe, 1997); or in a two-sector RBC model with sector-specific productive externalities (Benhabib and Farmer, 1996; Perli, 1998; and Harrison, 2001), the critical level of technological increasing returns needed for equilibrium multiplicity is much less stringent than that in Benhabib and Farmer's (1994) representative-agent macroeconomy. Accordingly, incorporating one of the aforementioned features into our benchmark model is expected to yield the result that local indeterminacy can occur under empirically 
realistic parameterizations. ${ }^{6}$ Since asserting the empirical plausibility of self-fulfilling competitive equilibria is not the objective of this paper, we plan to pursue these research projects in the future.

\section{Alternative Economy}

In this section, we will explore the local (in)stability properties of an identical one-sector monopolistically competitive real business cycle model, but with a slightly different production function for intermediate goods-producing firms. In particular, we follow Chang, Hung and Huang (2011) and postulate that the technology of producing the $j$ 'th intermediate input is given by

$$
x_{j t}=k_{j t}^{a} h_{j t}^{b}\left(K_{t}^{a \phi_{K}} H_{t}^{b \phi_{H}}\right)-F, a, b, \phi_{k}, \phi_{H}, F>0 \text { and } a+b=1,
$$

where $\phi_{K}$ and $\phi_{H}$ represent the degrees of positive productive externalities generated from the economy-wide levels of capital and labor services, respectively. ${ }^{7}$ It follows that besides the fixed overhead costs $F$, the existence of additional increasing returns-to-scale in (23) is derived from external effects, rather than from an internal channel through intermediate-good firms' own factor inputs à la (3).

Next, we follow the same solution procedure as in section 2 to find that equation (2) on the demand function for $x_{j t}$ will remain the same, and that the equilibrium quantity or size of intermediate good $j$ is changed to

$$
x_{j t}=\frac{\lambda F}{1-\lambda}>0 .
$$

At the model's symmetric equilibrium defined by condition (7), the measure of intermediategood producers becomes

$$
N_{t}=\frac{(1-\lambda) K_{t}^{a\left(1+\phi_{K}\right)} H_{t}^{b\left(1+\phi_{H}\right)}}{F}>0 ;
$$

the resulting reduced-form social technology that displays increasing returns to specialization is

\footnotetext{
${ }^{6}$ Pavlov and Weder (2012) examine endogenous business cycles in a two-sector monopolistically competitive $\mathrm{RBC}$ model with a unique set of intermediate inputs that are used in the production of both consumption and investment goods; acyclical/countercyclical/procyclical markups; together with fixed or variable capital utilization.

${ }^{7}$ As in Devereux, Head and Lapham $(1993,1996,2000)$, the degree of returns to specialization in the ChangHung-Huang economy is postulated as $\theta=\frac{1}{\lambda}-1>0$. Therefore, the market-power parameter $\lambda$ also governs the strength of product-variety effects.
} 


$$
Y_{t}=N_{t}^{1+\theta} x_{t}=\lambda\left[\frac{1-\lambda}{F}\right]^{\theta}\left[K_{t}^{a\left(1+\phi_{K}\right)} H_{t}^{b\left(1+\phi_{H}\right)}\right]^{1+\theta},
$$

where $a\left(1+\phi_{K}\right)(1+\theta)<1$ such that sustained economic growth is not allowed, and the degree of aggregate returns-to-scale in production is equal to $\left(1+a \phi_{K}+b \phi_{H}\right)(1+\theta)$; the price of each intermediate input, as in (10), remains unchanged; and the prices of factor inputs are

$$
r_{t}=a \frac{Y_{t}}{K_{t}} \quad \text { and } \quad w_{t}=b \frac{Y_{t}}{H_{t}}
$$

therefore the capital and labor shares of national income are given by $a$ and $b$, respectively. It is then straightforward to obtain an autonomous pair of differential equations in $k_{t}$ and $c_{t}$ that summarize this economy's equilibrium conditions, followed by deriving the determinant and trace of the associated Jacobian matrix:

$$
\text { Det }=\underbrace{\left[\frac{(\rho+\delta)(b \delta+\rho)}{a}\right]}_{\text {positive }}\left\{\frac{(1+\gamma)\left[a\left(1+\phi_{K}\right)(1+\theta)-1\right]}{1+\gamma-b\left(1+\phi_{H}\right)(1+\theta)}\right\},
$$

and

$$
\operatorname{Tr}=\frac{\delta(1+\gamma)\left[\theta+\phi_{K}(1+\theta)\right]+\rho(1+\theta)\left[(1+\gamma)\left(1+\phi_{K}\right)-b\left(1+\phi_{H}\right)\right]}{1+\gamma-b\left(1+\phi_{H}\right)(1+\theta)} .
$$

We note that as in our baseline macroeconomy, the monopolistic-markup parameter $\lambda$ does not enter the expressions of (28) and (29), thus it exerts no influence on the model's equilibrium dynamics. In addition, since the parametric restriction of $a\left(1+\phi_{K}\right)(1+\theta)<1$ rules out the possibility of endogenous growth, the Jacobian's determinant (28) is positive if and only if

$$
b\left(1+\phi_{H}\right)(1+\theta)-1>\gamma,
$$

which provides a necessary condition for the occurrence of an indeterminate steady state, as well as leading to a negative denominator in (29). It follows that the model's Jacobian matrix possesses a negative trace when its numerator is positive, which in turn imposes a lower bound on the magnitude of capital externality:

$$
\phi_{K}>\underbrace{\frac{\rho\left[b\left(1+\phi_{H}\right)(1+\theta)-(1+\gamma)(1+\theta)\right]-\delta \theta(1+\gamma)}{(\rho+\delta)(1+\gamma)(1+\theta)}}_{\equiv \phi_{K}^{\min }} .
$$


Using the inequality of (30) to substitute out the first term inside the bracket on the righthand-side of equation (31), it is straightforward to show that $\phi_{K}^{\min }>-\frac{\theta}{1+\theta}$, which is smaller than zero. This implies that the requisite (31) holds true for all positive values of $\phi_{K}$, and hence (30) is the necessary and sufficient condition for our alternative economy to exhibit equilibrium indeterminacy and sunspot-driven business cycles $(\operatorname{Tr}<0<\operatorname{Det}){ }^{8}$

As in the preceding section, a two-part comparative analysis is carried out on condition (30) to acquire further understanding. First, substituting $\theta=0$ into equation (26) shows that in sharp contrast to our benchmark formulation, the social technology will exhibit increasing returns-to-scale in $K_{t}$ and $H_{t}$ due to the presence of positive external effects. It follows that equilibrium multiplicity may still arise within the modified model under no returns to specialization. This finding indicates that the existence of sufficiently strong productive externalities from aggregate labor hours alone (without any variety effects), specifically $\phi_{H}>\frac{1+\gamma}{b}-1$, is able to generate belief-driven cyclical fluctuations in our alternative macroeconomy. Second, per the notations used in this section, the requisite condition for local indeterminacy in Benhabib and Farmer's (1994) one-sector RBC framework becomes

$$
\frac{b}{\lambda}-1>\gamma
$$

which involves intermediate-input firms' monopolistic power because $\lambda$ now influences the economy's symmetric-equilibrium prices of intermediate goods and factor inputs. After comparing (30) versus (32), we find that the parametric scope for endogenous business cycles is larger (smaller) in our alternative model than that in the Benhabib-Farmer setting provided $\left(1+\phi_{H}\right)(1+\theta)>(<) \frac{1}{\lambda}$. This in turn implies that the required parameterizations for sunspot-driven cyclical fluctuations will be quantitatively different between these two model economies. In particular, the sign for the preceding inequality is determined by the combined effects of labor externalities and returns to specialization versus the markup ratio of price over marginal costs.

On the other hand, the intuitive interpretation of condition (30) is qualitatively the same as (21) for the macroeconomy analyzed in section 2; or (32) for the Benhabib-Farmer formulation, i.e. the equilibrium wage-hours locus is positively sloped and steeper than the household's labor supply curve. However, we will show below that the feasible parametric region which yields indeterminacy and sunspots in the modified model is ceteris paribus larger than its baseline counterpart. Using the equivalent calibrations - the labor share of national income

\footnotetext{
${ }^{8}$ As mentioned in footnote 7, Chang, Hung and Huang (2011) postulate that $\theta=\frac{1}{\lambda}-1$ in their analytical framework. After substituting this one-to-one relationship between $\lambda$ and $\theta$ into (30), we will recover the indeterminacy condition for the Chang-Hung-Hunag economy: $b\left(1+\phi_{H}\right)>\lambda(1+\gamma)$.
} 
$b=0.7$ and the wage elasticity of hours worked $\gamma=0$ - as before, Figure 1 depicts the resulting local (in)stability properties by dividing the $\phi_{H}-\theta$ space into areas of "Saddle" and "Sink". Since the inequalities of (21) and (30) coincide under no external technological effect of labor $\left(\phi_{H}=0\right)$, the numerical experiment in the previous section and the vertical axis of Figure 1 together demonstrate that the threshold levels of returns to specialization needed for macroeconomic instability, given by $\theta \geq 0.4286$, will be equalized across the two specifications of our model that allows for endogenous entry and exit. When the size of labor externality rises and becomes more positive, the minimum degree of variety effects that generates local indeterminacy will fall $\left(\frac{\partial \theta_{\min }}{\partial \phi_{H}}<0\right)$, as shown by the downward-sloping curve for the lower bound of the "Sink" region in Figure 1. Intuitively, this finding illustrates two cooperating factors in producing multiple equilibria within a one-sector monopolistically competitive RBC framework: either an increase in labor externality or an expansion in product variety will raise the aggregate output elasticity with respect to hours worked (see equation 26), which in turn helps justify agents' self-fulfilling anticipations about future economic activities. By contrast, condition (21) shows that only the returns-to-specialization parameter $\theta$ is available to affect equilibrium dynamics of the benchmark model. As a result, while keeping the calibrated values of other parameters unchanged, our alternative macroeconomy is quantitatively more likely to display endogenous business cycles because the requisite $\theta_{\min }$ will be relatively lower.

With regard to the empirical plausibility of the critical level of aggregate returns-to-scale in production needed for equilibrium indeterminacy, which is equal to $\left(1+a \phi_{K}+b \phi_{H}\right)\left(1+\theta_{\min }\right)$ in the modified model, we note that previous studies do not present separate point estimates on the degrees of capital and labor externalities. Under the commonly-adopted configuration of $\phi_{K}=\phi_{H}>0$, it is straightforward to show that along the negatively-sloped dividing locus in Figure 1, the threshold degree of technological increasing returns required for an indeterminate steady state to occur is the same $(=1.4286)$ for all feasible combinations of $\phi_{H}$ and $\theta$. Such a requirement turns out to be identical to that for our illustrative example in the baseline macroeconomy which does not exhibit any productive externalities. For the sake of theoretical completeness, we also examine the extreme case of no capital externality $\phi_{K}=0$ within the alternative model. Given the highest possible value of $\phi_{H}=0.4$ considered in Figure 1, the minimum returns to specialization that leads to indeterminate equilibria will be very small, given by $\theta_{\min }=0.0204$. This particular $\left\{\phi_{K}, \phi_{H}, \theta_{\min }\right\}$ combination in turn yields an aggregate level of returns-to-scale to be 1.3061, which remains unrealistically high vis-à-vis the upper bounds of estimated confidence intervals reported in Burnside (1996), Basu and Fernald (1997), and Laitner and Stolyarov (2004), among others. Nevertheless, the 
preceding numerical experiments have verified that it is quantitatively easier for our alternative economy to display belief-driven cyclical fluctuations than the benchmark formulation. In sum, our quantitative analysis shows that whether macroeconomic instability arises in a onesector monopolistically competitive RBC model or not depends crucially on the production specifications of intermediate goods-producing firms.

\section{Conclusion}

This paper examines the theoretical as well as quantitative interrelations between equilibrium indeterminacy, endogenous entry/exit of intermediate-input producers, and increasing returns to specialization within two versions of a parsimonious one-sector monopolistically competitive real business cycle model. Other than the common fixed set-up costs, additional increasing returns-to-scale for producing intermediate goods in the baseline framework are initiated from operational firms' own factor inputs, whereas positive productive externalities from the economy-wide levels of capital and labor services are the sources in the alternative setting. While the underlying economic mechanisms are different, we analytically show that the necessary and sufficient conditions for the occurrence of endogenous business cycle fluctuations in both specifications turn out to be qualitatively identical to that in Benhabib and Farmer's (1994, section 2.2) macroeconomy. That is, the equilibrium wage-hours locus must be upward sloping, and steeper than the labor supply curve such that agents' initial optimism will become self-fulfilling. We also find that the parameter which governs intermediate goods-producing firms' market power does not play any role in affecting the local (in)stability stabilities of either formulation. In addition, the minimum degree of aggregate returns-to-scale in production needed for multiple equilibria within our benchmark or modified model is implausible high vis$\grave{a}$-vis estimation results of previous empirical studies; but this is not a serious issue of concern in light of recent theoretical developments in the RBC-based indeterminacy literature. Finally, our calibrated analysis shows that ceteris paribus the alternative economy is more susceptible to indeterminacy and sunspots than the baseline counterpart. This numerical result in turn highlights the significant importance of intermediate-input producers' production structures on the feasible parametric region that exhibits belief-driven cyclical fluctuations within a onesector representative-agent macroeconomy under monopolistic competition, free entry and exit of firms, and increasing returns to product variety. 


\section{References}

[1] Ardelean, A. (2011), "How Strong is the Love of Variety?" Unpublished Manuscript, Santa Clara University.

[2] Basu, S., and J.G. Fernald (1997), "Returns to Scale in U.S. Production: Estimates and Implications," Journal of Political Economy 105, 249-283.

[3] Bénassy, J.-P. (1996), "Monopolistic Competition, Increasing Returns to Specialization and Output Persistence," Economic Letters 52, 187-191.

[4] Benhabib, J. and R.E.A. Farmer (1994), "Indeterminacy and Increasing Returns," Journal of Economic Theory 63, 19-41.

[5] Benhabib, J. and R.E.A. Farmer (1996), "Indeterminacy and Sector-Specific Externalities," Journal of Monetary Economics 37, 421-444.

[6] Benhabib, J. and R.E.A. Farmer (1999), "Indeterminacy and Sunspots in Macroeconomics," in J. Taylor and M. Woodford, eds., Handbook of Macroeconomics, Amsterdam: North Holland, 387-448.

[7] Bernard, A.B., S.J. Redding and P.K. Schott (2010), "Multi-Product Firms and Product Switching," American Economic Review 100, 70-97.

[8] Broda, C. and D.E. Weinstein (2010), "Product Creation and Destruction: Evidence and Price Implications," American Economic Review 100, 691-732.

[9] Burnside, C. (1996), "Production Function Regression, Returns to Scale, and Externalities," Journal of Monetary Economics 37, 177-201.

[10] Chang, J.-J., H.-W. Hung and C.-C. Huang (2011), "Monopoly Power, Increasing Returns to Variety, and Local Indeterminacy," Review of Economic Dynamics 14, 384-388.

[11] Davis, S.J. and J. Haltiwanger (1990), "Gross Job Creation and Destruction: Microeconomic Evidence and Macroeconomic Implications," National Bureau of Economic Research Macroeconomics Annual 5, 126-168.

[12] Devereux, M.B., A.C. Head and B.J. Lapham (1993), "Monopolistic Competition, Technology Shocks and Aggregate Fluctuations," Economic Letters 41, 57-61.

[13] Devereux, M.B., A.C. Head and B.J. Lapham (1996), "Monopolistic Competition, Increasing Returns, and the Effects of Government Spending," Journal of Money, Credit and Banking 28, 233-254.

[14] Devereux, M.B., A.C. Head and B.J. Lapham (2000), "Government Spending and Welfare with Returns to Specialization," Scandinavian Journal of Economics 102, 547-561.

[15] Feenstra, R.C. and H.L Kee, (2008), "Export Variety and Country Productivity: Estimating the Monopolistic Competition Model with Endogenous Productivity," Journal of International Economics 74, 500-518.

[16] Funke, M. and R. Ruhwedel (2001), "Product Variety and Economic Growth: Empirical Evidence for the OECD Countries," IMF Staff Papers 48, 225-242.

[17] Harrison, S.G. (2001), "Indeterminacy in a Model with Sector-Specific Externalities," Journal of Economic Dynamics and Control 25, 747-764.

[18] Jaimovich, N. and M. Floetotto (2008), "Firm Dynamics, Markup Variations and the Business Cycle," Journal of Monetary Economics 55, 1238-1252. 
[19] Kim, J. (2004), "What Determines Aggregate Returns to Scale," Journal of Economic Dynamics and Control 28, 1577-1594.

[20] Laitner, J. and D. Stolyarov (2004), "Aggregate Returns to Scale and Embodied Technical Change: Theory and Measurement using Stock Market Data," Journal of Monetary Economics 51, 191-233.

[21] Pavlov, O. and M. Weder (2012), "Variety Matters," Journal of Economic Dynamics and Control 36, 629-641.

[22] Perli, R. (1998), "Indeterminacy, Home Production, and the Business Cycle: A Calibrated Analysis," Journal of Monetary Economics 41, 105-125.

[23] Schmitt-Grohé, S. and M. Uribe (1997), "Balanced-Budget Rules, Distortionary Taxes and Aggregate Instability," Journal of Political Economy 105, 976-1000.

[24] Wen, Y. (1998), "Capacity Utilization Under Increasing Returns to Scale," Journal of Economic Theory 81, 7-36. 


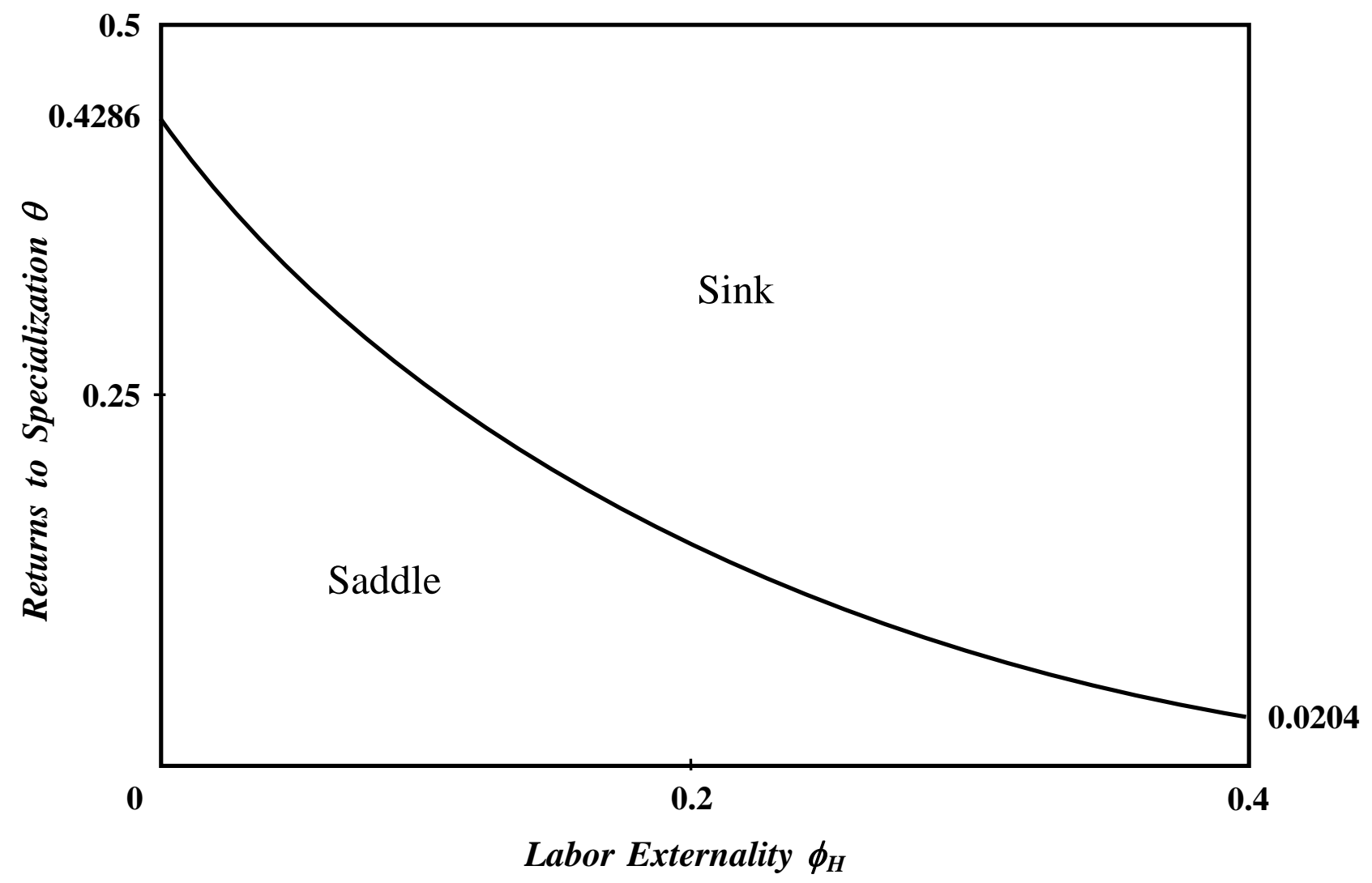

Figure 1. Local Stability Properties of the Alternative Economy 